\title{
Human papilloma virus infection and fascin over-expression in squamous cell carcinoma of the cervix
}

\author{
Zohreh Yousefi Ghalejoogh ${ }^{1}$, Simin Mirakhor Samani², Somayeh Shatizadeh Malekshahi \\ Reza Shahsiah ${ }^{4}$, Jila Yavarian' ${ }^{1}$, Seyed Jalal Kiani*5
}

\section{Abstract}

Background: Human papilloma virus (HPV) is involved in development of almost all cervical cancers, mainly through the subversion of cellular mechanisms of growth control. Fascin plays central role in subsequent cell transformation events. Fascin mediates stabilization of parallel actin bundles where cellular protrusions are formed; this represents primary stages of cell migration and metastasis. Immunohistochemical assays have shown up-regulation of fascin expression in many epithelial and non-epithelial neoplasms. Therefore, the aim of this study was to investigate HPV infection and fascin expression in samples of cervical cancer.

Methods: Of 66 patients with confirmed SCC, formalin-fixed specimens, embedded in paraffin blocks were evaluated for HPV infection with nested multiplex polymerase chain reaction (NM-PCR) and for fascin expression with immunohistochemical assays. Statistical analysis was performed using Wilcoxon rank-sum test and SPSS software. A $p<0.05$ was considered for statistical significance.

Results: Of 66 samples, 52 (78.7\%) were found positive for HPV infection and fascin over-expression was shown in all squamous cell carcinoma samples.

Conclusion: This study showed fascin overexpression in squamous cell carcinoma of the cervix which might be involved in metastasis of cancers induced by some types of HPV, hypothetically through attenuation of inter-cellular adhesions, and induction of cell motility.

Keywords: Fascin, Human Papilloma Virus, Squamous Cell Carcinoma

Conflicts of Interest: None declared

Funding: Tehran University of Medical Sciences

\section{*This work has been published under CC BY-NC-SA 1.0 license.}

Copyright $\odot$ Iran University of Medical Sciences

Cite this article as: Yousefi Ghalejoogh Z, Mirakhor Samani S, Shatizadeh Malekshahi S, Shahsiah R, Yavarian J, Kiani SJ. Human papilloma virus infection and fascin over-expression in squamous cell carcinoma of the cervix. Med J Islam Repub Iran. 2018 (31 Dec);32:134. https://doi.org/10.14196/mjiri.32.134

\section{Introduction}

Cervical cancer is the fourth most common cancer in women throughout the world. Annually, 530000 incidents and approximately 270000 deaths are estimated which is a global health issue. In under-developed countries, with limited access to effective screening programs and lack of subsequent treatment for pre-cancerous lesions, cancer of the cervix is the most common cause of cancer-related death

\footnotetext{
Corresponding author:Dr Seyed Jalal Kiani, kiani.j@iums.ac.ir

1. Virology Department, School of Public Health, Tehran University of Medical Sciences, Tehran, Iran

2. Department of Pathology, Qazvin University of Medical Sciences, Qazvin, Iran

3. Department of Virology, School of Medical Sciences, Tarbiat Modarres University, Tehran, Iran

4. Pathology Department, School of Medicine, Tehran University of Medical Sciences, Tehran, Iran

5. Department of Virology, School of Medicine, Iran University of Medical Sciences, Tehran, Iran
}

(1).

Human papilloma virus (HPV) is responsible for development of almost all cervical cancers. The infection with high-risk HPVs, especially types 16 and 18, has strong correlations with the establishment of squamous cell carcinoma and cervical adenocarcinoma, respectively (2). These DNA viruses can directly subvert mechanisms involved in $\uparrow$ What is "already known" in this topic:

Human papilloma virus (HPV) is involved in the development of almost all cervical cancers, mainly through the subversion of cellular mechanisms of growth control. Fascin mediates stabilization of parallel actin bundles where cellular protrusions are formed; this may represent primary stages of cell migration and metastasis.

$\rightarrow$ What this article adds:

The present study showed fascin overexpression in all squamous cell carcinoma samples of the cervix which might be due in part to trans-activation of FSCN promoters by E6/E7 oncoproteins of HPVs. 
cellular growth control. In fact, after genome integration, removal of E2-mediated repressive control on viral E6 and E7 oncoproteins leads to degradation of pRb and p53 cellular proteins and cell cycle progression through S-phase (3). E7 binds to $\mathrm{pRb}$ and its associated pocket proteins $\mathrm{p} 107$ and p130 and destroys E2F/pRb interactions of cell-cycle control (4). E6 not only interacts with p53 and prohibits p53-induced apoptosis, but also activates telomerase reverse transcriptase (TERT) and plays key role in keratinocyte immortalization(5). Persistent infection accompanied with deregulation of cell cycle controls results in genome instability and induction of oncogenic mutations which may finally lead to cell transformation.

Transformation is known mostly by several phenotypic modifications, including alterations of cell shape, motility, anchorage dependency, and cell-cell contacts. These modifications involve rearrangement of microfilament cytoskeleton, especially in the cell periphery, where fascin is usually found as an actin cross-linking protein (6).

Fascin plays a central role in the formation of two cellular actin-based structures, including cortical protrusions (i.e., filopodia, spikes, lamellipodial ribs, dendrites, and microvilli), and microfilament bundles (7). Fascin mediates stabilization of parallel actin bundles where cellular protrusions are formed; this represents primary stages of cell migration when it is required in physiologic or neoplastic settings. High levels of fascin expression occur in the brain (neurons, glial cells, and endothelial cells), ovary and testis (8) but it is absent or has limited expression in epithelial cells. However, immunohistochemical assays have shown up-regulation in fascin expression in many epithelial and non-epithelial neoplasms (9), including lymphomas, glioblastomas and carcinomas, where its overexpression correlates with increased tumor metastasis and invasiveness (10).

As a result, fascin can be used as a marker in the diagnosis and prognosis of different cancer types (10), including squamous cell carcinoma (SCC) of the cervix. Therefore, this investigation was performed to study HPV infection and fascin expression in samples of cervical cancer to analyze the potential correlation between fascin expression and transformation of squamous cell epithelium of the cervix.

\section{Methods \\ Samples}

Of 66 patients with confirmed SCC, formalin-fixed specimens, embedded in paraffin blocks were collected from the Department of Pathology at Imam Khomeini Hospital, Tehran, Iran. Hematoxylin and eosin-stained tissue sections for each specimen were evaluated by an experienced pathologist to define the most appropriate tissue area. These were evaluated for HPV infection with nested multiplex polymerase chain reaction (NM-PCR) and for fascin expression with immunohistochemical assays.

DNA extraction and polymerase chain reaction for HPV detection

For each paraffin-embedded block, sections were cut at eight-micrometer thickness, and DNA extraction was performed using the phenol-chloroform protocol and ethanol precipitation, as described previously (11). Nested multiplex PCR (NMPCR) was performed for detection of HPV types 16, 18, 31, and 33 (high-risk) as well as types 6 and 11 (low-risk), as described before (11). Concisely, the first run of NMPCR was carried out using consensus GP-E6/E7 primers, which are able to amplify a genomic region common in all mucosal HPV genotypes. The second run of NMPCR was done with 2 type-specific multiplex PCR primer cocktails (11). The size of each PCR product determined individual HPV types.

\section{Immunohistochemistry}

Tissue sections of eight-micrometer thickness were taken from paraffin-embedded blocks using a standard microtome (Leica SM2000, Wetzlar, Germany) and mounted onto microscope slides for analysis. For heat-induced antigen retrieval, after dewaxing and rehydration, all slides were subjected to microwave treatment $(3 \times 5 \mathrm{~min}$ each, 600 $\mathrm{W}$, in $10 \mathrm{mM}$ citrate buffer, $\mathrm{pH} 6.0$ ). The slides were then immersed into $3 \% \mathrm{H} 2 \mathrm{O} 2$ and $100 \%$ methanol in order to block endogenous peroxidase activity. Then, the slides were subjected to overnight incubation at $4{ }^{\circ} \mathrm{C}$ with mouse monoclonal anti-fascin antibody (1:50; Dako) and treated with biotinylated anti-mouse secondary antibody (1:100; DAKO). Finally, the slides were incubated with streptavidin-peroxidase (1:100; Dianova), and DAB/H2O2 (1.85 mM). PBS was used for all washing procedures. Haematoxylin was used for counterstaining the slides. As negative control, PBS was used instead of primary antibody. In addition, the endothelium tissues were considered as positive control of staining.

\section{Immunohistochemical evaluation}

A modified scoring system based on the semiquantitative score explained by Bittinger et al. (12) was applied for analyzing the intensity and extent of the staining reaction. For each specimen the intensity of staining was scored as $1=$ none, $2=$ weak, $3=$ moderate, or $4=$ strong. The percentage of stained tumor cells were scored as $1=0-10 \%, 2=11-$ $50 \%, 3=51 \pm 80 \%$, or $4=81-100 \%$.

\section{Statistical analysis}

Statistical analysis was performed using Wilcoxon ranksum test and SPSS software, version 20.0 (SPSS Inc., Chicago). A $\mathrm{p}<0.05$ was considered for statistical significance.

\section{Results}

\section{HPV Detection}

HPV infection was detected in 78.7\% (52/66) of cervical cancer samples. The most prevalent type of HPV, among six investigated types $(16,18,31,33,6$, and 11) was type 16 with $60.6 \%(40 / 66)$. In $10.6 \%$ of cases, coinfection with two types of HPV was reported (Fig. 1).

\section{Fascin Immunostaining}

Fascin expression was observed as a fine, granular to diffuse cytoplasmic pattern. Figure 2 demonstrates the results 


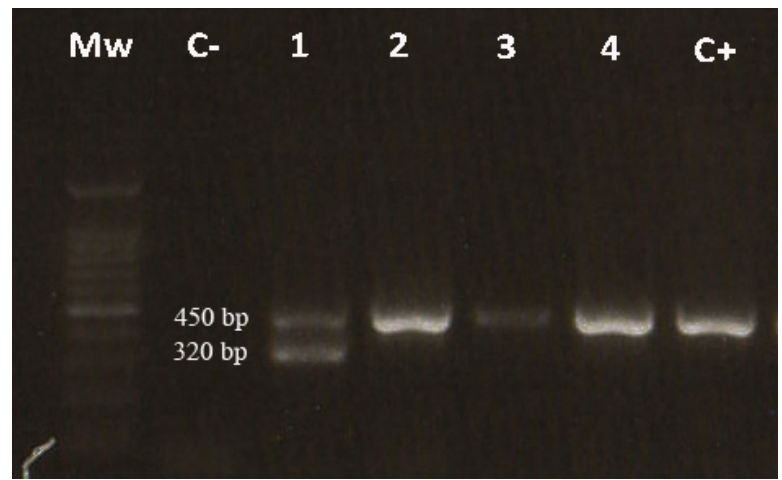

Fig. 1. HPV detection by nested multiplex PCR assay. The identification of bands with 457 bp and 322 bp indicates HPV types 16 and 18 , respectively. Lane 1 represents co-infection with these 2 types. Mw: Molecular weight; C-: Negative Control; C+: Positive Control.

of fascin immunostaining in normal and transformed tissues of the cervix.

Fascin expression was observed in all cases $(100 \%)$ of cervical carcinoma $(\mathrm{p}<0.001)$. Among 66 positively stained cervical carcinoma cases, $43(65.2 \%)$ showed the highest percentage of tumor staining. On the other hand, 46 $(69.7 \%)$ of samples showed intensities less than the control. Surprisingly, in our study, no sample showed intensity more than endothelial control.

The relationship features were investigated to assess the significance of fascin overexpression in cervical carcinoma. Fascin expression was not correlated with age, but fascin overexpression was significantly correlated with cervical carcinoma $(\mathrm{p}<0.001)$.

The results of fascin overexpression in samples infected with different HPV genotypes were summarized in Table 1. Type $16(58.2 \%)$ was the most prevalent HPV type among samples with fascin overexpression, followed by coinfection with types 16 and $18(7 \%)$.
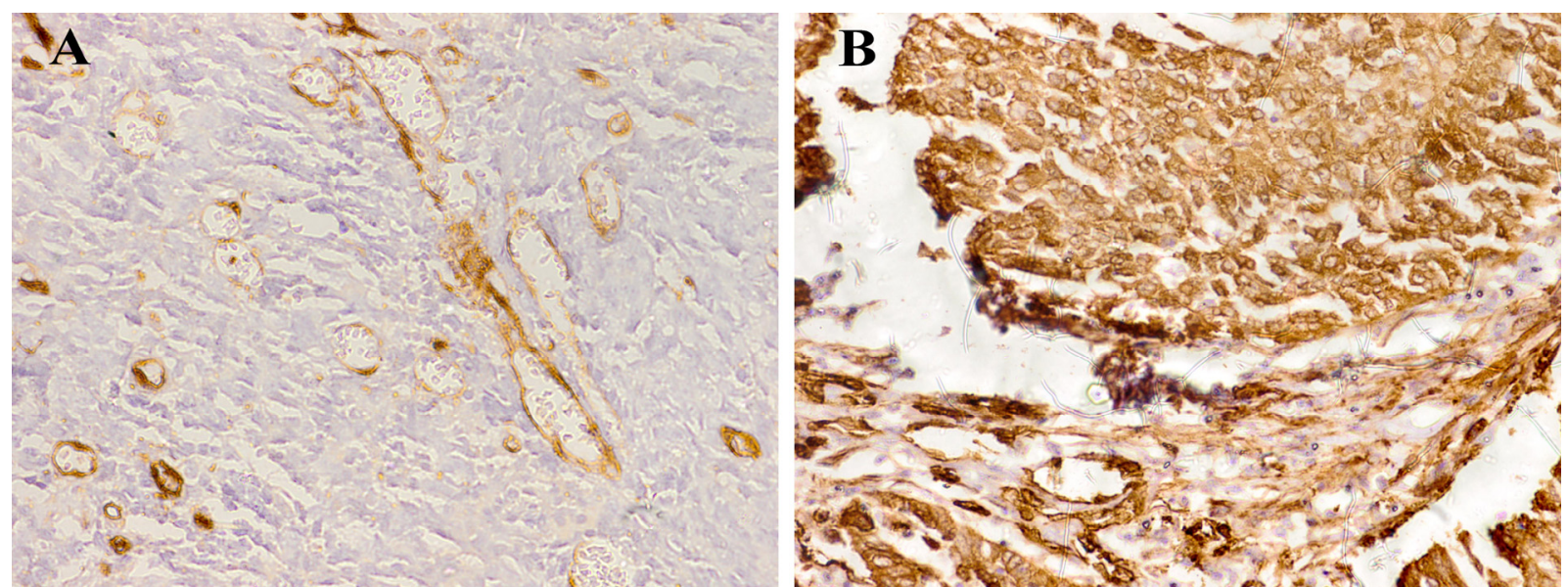

Fig. 2. Immunohistochemical evaluation of fascin expression in the epithelium of the cervix. A) Fascin expression in normal epithelial cells of the cervix. B) Over-expression of Fascin in squamous cell carcinoma of the cervix.

Table 1. Fascin overexpression with regard to different HPV genotypes

\begin{tabular}{ccccccc}
\hline & \multicolumn{7}{c}{ HPV types } & HPV Negative \\
\cline { 2 - 7 } & 16 & $16 \& 18$ & $16 \& 6$ & 18 & 31 & 6 \\
Fascin-overexpression & $25(58.2 \%)$ & $3(7 \%)$ & $1(2.3 \%)$ & $1(2.3 \%)$ & $1(2.3 \%)$ & $1(2.3 \%)$ \\
\hline
\end{tabular}


al. (9) showed that normal squamous epithelium has fascin immunoreactivity in basal and parabasal cells and normal endocervical epithelium did not express fascin. On the other hand, the endothelial cells of the cervix show consistent staining for fascin. They reported increasing staining in most CIN lesions and more frequent fascin positivity in invasive SCC, which is a possible indicator of invasion.

On the other hand, Ghabreau et al. (29) showed an association between fascin overexpression and the expression of high-risk papilloma viruses E6/E7 oncoproteins in colorectal cancer (CRC). An increase in fascin expression has also been shown in CRC samples in comparison with normal colorectal tissues $(7,30)$. They suggested that E6/E7 oncoproteins of high-risk papilloma viruses may affect expression levels of several cellular genes including fascin via regulation of their promoter activity (29). Moreover, Lu et al. (31) showed that transcriptional activation of FSCN1 promoter is mediated by native Specificity protein 1 (Sp1). The activity of $\mathrm{Sp} 1$ is regulated through ERK1/2 pathway. This pathway plays role in Sp1-dependent activation of FSCN1 promoter. They also hypothesized that EGF can upregulate fascin expression, both in mRNA and protein levels. Activation of ERK1/2-Sp1 signaling pathway as well as the enhancement of Sp1 binding to DNA may be involved in this issue.

\section{Conclusion}

In conclusion, fascin overexpression decreases inter-cellular adhesions, increases motility of epithelial cells, and has been shown in different cancers of humans. This study also showed fascin overexpression in squamous cell carcinoma of the cervix which might be involved in metastasis of cancers induced by some types of HPV. Considering the relationship between fascin expression and tumor invasiveness, this marker can be used as a tool to investigate tumor cells behavior and risk of their invasion to other parts of the body.

\section{Acknowledgements}

This research was supported in part by Tehran University of Medical Sciences (grant No 91-02-27-18407). All the support from Pathobiology Laboratory members of Imam Khomeini Hospital is greatly appreciated.

\section{Conflict of interest}

The authors declare that they have no conflict of interest.

\section{References}

1. World Health Organization. Human papillomavirus (HPV) and cervical cancer 2016 [updated June 2016. Available from: http://www.who.int/ mediacentre/factsheets/fs380/en/.

2. Clifford G, Smith J, Plummer M, Munoz N, Franceschi S. Human papillomavirus types in invasive cervical cancer worldwide: a metaanalysis. Br J Cancer. 2003;88(1):63-73.

3. Pett MR, Alazawi WO, Roberts I, Dowen S, Smith DI, Stanley MA, et al. Acquisition of high-level chromosomal instability is associated with integration of human papillomavirus type 16 in cervical keratinocytes. Cancer Res. 2004;64(4):1359-68.

4. Yeo-Teh N, Ito Y, Jha S. High-risk human papillomaviral oncogenes E6 and E7 target key cellular pathways to achieve oncogenesis. Int J Mol Sci. 2018; 19(6):1706.
5. Howie HL, Katzenellenbogen RA, Galloway DA. Papillomavirus E6 proteins. Virology. 2009;384(2):324-34.

6. Goncharuk VN, Ross JS, Carlson JA. Actin-binding protein fascin expression in skin neoplasia. J Cutan Pathol 2002;29(7):430-8.

7. Oh SY, Kim YB, Suh KW, Paek OJ, Moon HY. Prognostic impact of fascin-1 expression is more significant in advanced colorectal cancer. J Surg Res. 2012;172(1):102-8.

8. Hwang JH, Smith CA, Salhia B, Rutka JT. The role of fascin in the migration and invasiveness of malignant glioma cells. Neoplasia. 2008;10(2):149-59.

9. Koay M, Crook M, Stewart C. Fascin expression in cervical normal squamous epithelium, cervical intraepithelial neoplasia, and superficially invasive (stage IA1) squamous carcinoma of the cervix. Pathology. 2014;46(5):433-8.

10. Jansen S, Collins A, Yang C, Rebowski G, Svitkina T, Dominguez R. Mechanism of actin filament bundling by fascin. J Biol Chem. 2011;286(34):30087-96.

11. Kiani SJ, Malekshahi SS, Ghalejoogh ZY, Ghavvami N, Jandaghi NZS, Shahsiah R, et al. Detection and Typing of Human Papilloma Viruses by Nested Multiplex Polymerase Chain Reaction Assay in Cervical Cancer. Jundishapur J Microbiol. 2015;8(12).

12. Bittinger F, Brochhausen C, Köhler H, Lehr HA, Otto M, Skarke C, et al. Differential expression of cell adhesion molecules in inflamed appendix: correlation with clinical stage. J Pathol. 1998;186(4):422-8.

13. Yahyapour Y, Shamsi-Shahrabadi M, Mahmoudi M, Motevallian A, Siadati S, Shefaii S, et al. High-risk and low-risk human papillomavirus in esophageal squamous cell carcinoma at Mazandaran, Northern Iran. Pathol Oncol Res. 2013;19(3):385-91.

14. Salehi-Vaziri M, Sadeghi F, Alamsi-Hashiani A, Haeri H, Monavari $\mathrm{SH}$, Keyvani H. Merkel cell polyomavirus and human papillomavirus infections in cervical disease in Iranian women. Arch Virol. 2015;160(5):1181-7.

15. Salehi-Vaziri M, Sadeghi F, Bokharaei-Salim F, Younesi S, Alinaghi $\mathrm{S}$, Monavari SH, et al. The prevalence and genotype distribution of human papillomavirus in the genital tract of males in Iran. Jundishapur J Microbiol. 2015;8(12).

16. Salehi-Vaziri M, Sadeghi F, Hashemi FS, Haeri H, Bokharaei-Salim F, Monavari SH, et al. Distribution of human papillomavirus genotypes in Iranian women according to the severity of the cervical lesion. Iran Red Cresc Med J. 2016;18(4).

17. Massagué J, Batlle E, Gomis RR. Understanding the molecular mechanisms driving metastasis. Mol Oncol. 2017;11(1):3-4.

18. Svitkina T. The actin cytoskeleton and actin-based motility. Cold Spring Harbor Perspect Biol. $2018 ; 10(1)$ :a018267.

19. Kureishy N, Sapountzi V, Prag S, Anilkumar N, Adams JC. Fascins, and their roles in cell structure and function. Bioessays. 2002;24(4):350-61.

20. Chen SF, Lin CY, Chang YC, Li JW, Fu E, Chang FN, et al. Effects of small interfering RNAs targeting Fascin on gene expression in oral cancer cells. J Oral Pathol Med. 2009;38(9):722-30.

21. Gonzalez-Reyes C, Marcial-Medina C, Cervantes-Anaya N, CortesReynosa P, Salazar EP. Migration and invasion induced by linoleic acid are mediated through fascin in MDA-MB-231 breast cancer cells. Mol Cell Biochem. 2018;443(1-2):1-0.

22. Li J, Zhang S, Pei M, Wu L, Liu Y, Li H, Lu J, Li X. FSCN1 Promotes Epithelial-Mesenchymal Transition Through Increasing Snaill in Ovarian Cancer Cells. Cell Physiol Biochem. 2018;49(5):1766-77.

23. Hashimoto $Y$, Ito $T$, Inoue $H$, Okumura $T$, Tanaka E, Tsunoda $S$, et al. Prognostic significance of fascin overexpression in human esophageal squamous cell carcinoma. Clin Cancer Res. 2005;11(7):2597-605.

24. Hashimoto Y, Shimada Y, Kawamura J, Yamasaki S, Imamura M. The prognostic relevance of fascin expression in human gastric carcinoma. Oncology. 2004;67(3-4):262-70.

25. Maitra A, Iacobuzio-Donahue C, Rahman A, Sohn TA, Argani P, Meyer R, et al. Immunohistochemical validation of a novel epithelial and a novel stromal marker of pancreatic ductal adenocarcinoma identified by global expression microarrays: sea urchin fascin homolog and heat shock protein 47. Am J Clin Pathol 2002;118(1):52-9.

26. Jawhari AU, Buda A, Jenkins M, Shehzad K, Sarraf C, Noda M, et al. Fascin, an actin-bundling protein, modulates colonic epithelial cell invasiveness and differentiation in vitro. Am J Pathol. 2003;162(1):6980.

27. Pelosi G, Pastorino U, Pasini F, Maissoneuve P, Fraggetta F, Sonzogni A, et al. Independent prognostic value of fascin 
immunoreactivity in stage I nonsmall cell lung cancer. Br J Cancer. 2003;88(4):537-47.

28. Kabukcuoglu S, Oner U, Ozalp S, Bildirici K, Yalcin O, Colak E. The role of actin bundling protein fascin in the progression of ovarian neoplasms. Eur J Gynaecol Oncol 2006;27(2):171-6.

29. Ghabreau L, Segal ED, Yasmeen A, Kassab A, Akil N, Al Moustafa AE. High-risk human papillomavirus infections in colorectal cancer in the Syrian population and their association with Fascin, Id-1 and Pcadherin expressions: a tissue microarray study. Clin Cancer Investig J. 2012;1(1):26.

30. Van Marck V, Stove C, Jacobs K, Van den Eynden G, Bracke M. Pcadherin in adhesion and invasion: Opposite roles in colon and bladder carcinoma. Int J Cancer. 2011;128(5):1031-44.

31. Lu XF, Li EM, Du ZP, Xie JJ, Guo ZY, Gao SY, et al. Specificity protein 1 regulates fascin expression in esophageal squamous cell carcinoma as the result of the epidermal growth factor/extracellular signal-regulated kinase signaling pathway activation. Cell Mol Life Sci. 2010;67(19):3313-29. 